\title{
The influence of constructional features and of buildings on indoor Rn entry: experimental research in Catania city (Italy)
}

\author{
S. Lo Nigro ${ }^{1}$, F. Patania ${ }^{2}$, A. Gagliano ${ }^{2} \&$ F. Nocera ${ }^{2}$ \\ ${ }^{1}$ Physic Department \\ ${ }^{2}$ Energy and Environmental Division of D.I.I.M. \\ University of Catania, Italy
}

\begin{abstract}
The research, carried out for three years, take place within the sphere of ERRICCA (European Research into Radon Construction Concerted Action) funded in part by the European Commission and culminated in final workshop "Radon in The Living Environments" organized by National Technical University of Athens (April 1999). Authors held inquires and radiation measurements to seek out constructive features of buildings influencing Radon indoor admittance. The measured concentrations have been correlated with constructive features of buildings to discover the most significant connections. The results of research point-out that the buildings features and the placements of constructions on urban agglomeration are influent on $\mathrm{Rn}$ admittance into the indoor environments and allow the factors that producing indoor store of gas. At least, people built for, each general buildings typology, a general guidance that permits to choice the most suitable control technics to full down Rn concentrations to safe values for health of inhabitants.
\end{abstract}

\section{Sites, chain of equipments and techniques}

Research has been carried out in Catania city located near Etna volcano. Fig.1 shows both plans of city and placements and utilizations of checked buildings. The chain of measuring system has been formed by carcoil canisters, $\gamma$ spectrometer, PC with multi-channel data card and specific analysis software. People can find in (Lo Nigro and Patania,1999) calibration technics of 


\section{Environmental Health Risk}

equipments and techniques and formulas of measurements about the "efficiency", the "instrumental error", the "experimental error" and the "bottom and environmental radiation stability".



Figure 1:Plan of the City.

To calculate the Rn concentration has been applied formula suggested by U.S. EPA (Windham and Gray, 1987) slightly modified. To calculate MDA (Minimum Detectable Activity) has been applied formula:

$$
\mathrm{MDA}=3 \cdot \mathrm{B}^{\frac{0.5}{\tau}}
$$

where B is counting coming from "bottom radiation and $\tau$ is time (sec) of acquisition of B. People estimated MDA=0.1 sec between $25 \mathrm{KeV}$ and 609 
$\mathrm{KeV}$. To calculated MDC (Minimum Detectable Concentration) has been applied formula:

$$
\mathrm{MDA}=\frac{\mathrm{MDA}}{\mathrm{C}_{\mathrm{f}} \cdot \varepsilon \cdot \mathrm{T}_{\mathrm{f}} \cdot \mathrm{D}_{\mathrm{f}} \cdot \mathrm{P}_{\gamma}}
$$

where $C_{f}$ is the calibration factor $\left(\mathrm{m}^{3} / \mathrm{sec}\right), \varepsilon$ is the efficiency $(\mathrm{Cps} / \mathrm{Bq}), D_{\mathrm{f}}$ is the decay corrective factor, $T_{s}$ is the exposure time of canisters $(\mathrm{sec}), \mathrm{P}_{\gamma}$ is the probability of $\gamma$ radiations emission. Fig. 2 are one of $\gamma$-spectrometer diagram coming from measurements.

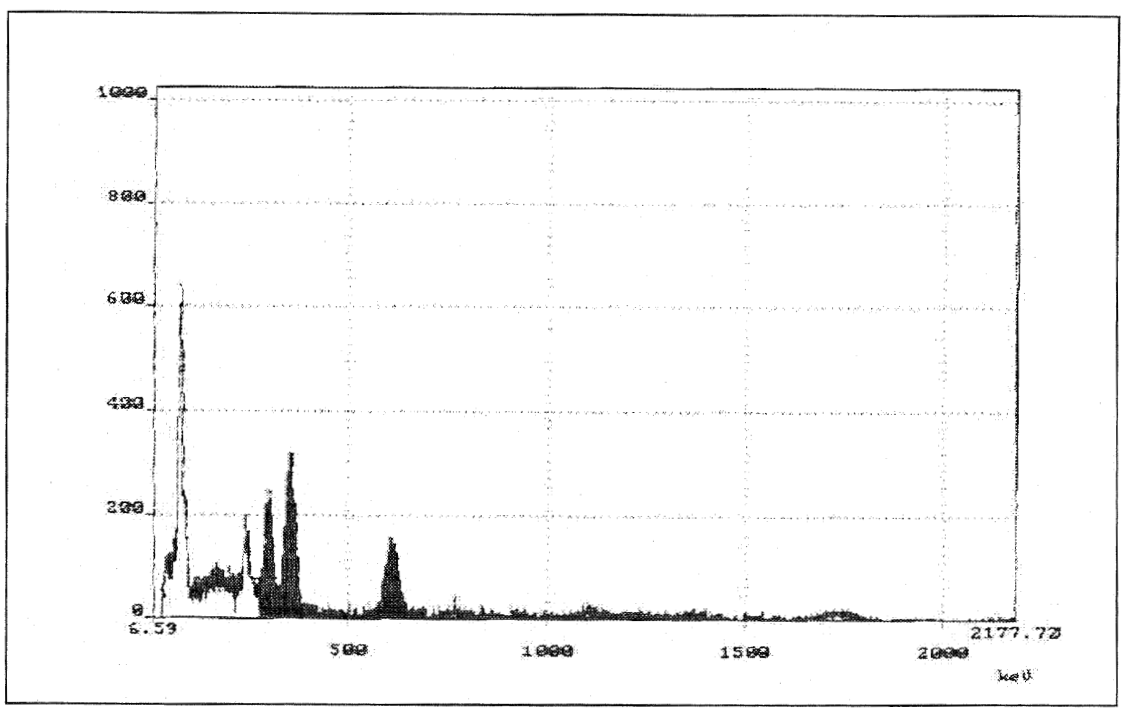

Figure 2:Example of $\gamma$-spectrometer diagram

\section{Comment of results}

Fig. 3 reports the general results of measurements and people can note that there are not warning concentrations in investigated buildings and it means that Catania city fortunately is not a quite polluted area in-fact only the $3.4 \%$ of measurements has gone up GPA limit $\left(150 \mathrm{~Bq} / \mathrm{m}^{3}\right)$. 


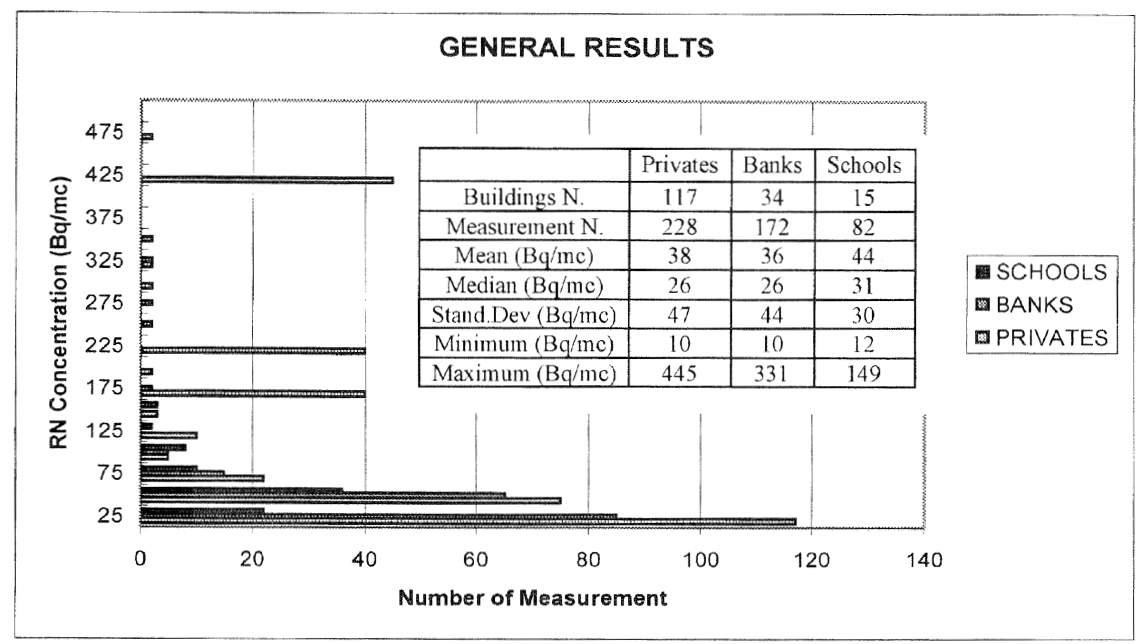

Figure 3:General Results

Fig. 4 shows that pollution decreases in direct function of height above soil and it means that significant Radon paths into the buildings are that ones coming from subsoil in accord with technical literature (Patania and Gagliano, 1994) People can observes too that there is an anomalous trend in the case of first floors both of private and bank buildings. The only reasonable way to try to explain this anomaly is to suppose that in the case of private buildings ground floors and mezzanines are used very often as commercial shops and private office premises, that is typologies of use with indoor air change bigger than that of first floors often utilized as private residence. Quite the same cause of anomaly for bank buildings where ground floors and mezzanines are spaces open to public. Fig. 5 highlights that pollution is in inverse relation with constructional age of buildings. This trend because buildings built in Catania before of the 1900 presents ancient constructional technics with basements in natural state without concrete slabs and proofings so that both foundations and filled-in boundary walls were built with high porous heaps of stones or lava rocks, materials that favour free entry of gas coming from subsoil into the basements and than into the buildings. In buildings built between the 1900 and the 1950 there is less pollution than that ones of previously constructional period because people began to utilize renforced concrete with proofing in basements and in foundations too, all factors that reduce entry of gas. After the 1950 the whole edifices were built with reinforced concrete hollow bricks with a lot of proofing and heat insulation materials that reduce more and more the entry likelihood of Radon.

Fig. 6 shows that indoor pollution increases moving from the old town centre to residential neighbourhood and suburbs. Before to try to explain this trend it is necessary to know that in Catania the prevalent source of Radon is that one coming from subsoil because very insignificant concentrations in natural water, 
in indoor air and in local building materials too have been measured. As in old town centre the must subsoil is done completely of cold lava flows originated from eruption of Etna volcano, it was very full of difficulties to excavate in this area basements or filled-in cellars or garages under the buildings because of the extreme hardness of lava stone. Moving towards external areas of centre, that is residential neighbourhoods and suburbs, the nature of subsoil changes in very less hardness materials favouring the construction under edifices of filled-in volumes that have increased that surfaces of buildings in contact with subsoil and consequently the likelihood of Rn entry.

Fig.7 shows the dependence of indoor Rn from the presence in buildings of HVAC plant. The presence of plants would favoured pollution decreasing as plants contribute to forced chance of air (Rudnick S.N et al., 1982). On the contrary, the results show higher levels in absence of plants than that in presence ones. After some investigations it has been possible to single out the cause of anomaly strictly coming from behavioural factors of buildings inhabitants. In fact Catania people do prefer do not open windows to change air when plants work to the aim to economise energy in winter time (air heating energy) and in summer time too (air conditioning energy). This behaviour of inhabitants, in synergy with presence of heat insulations that is impermeable to fluxes of Radon, causes store of gas in buildings.

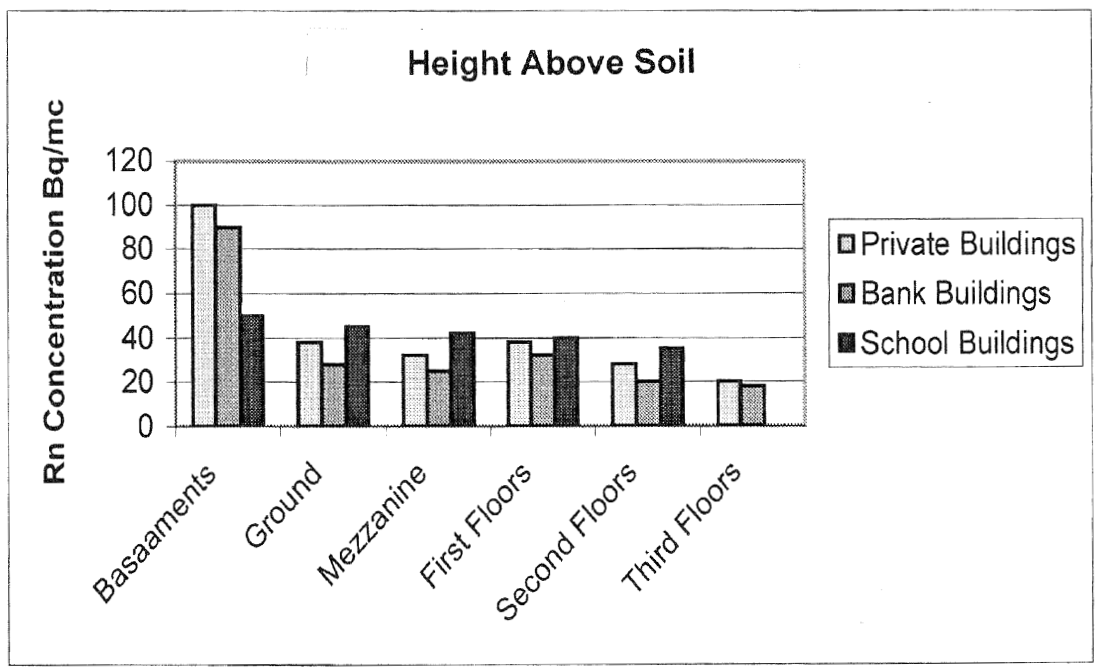

Figure 4:Height Above Soil 
48 Environmental Health Risk

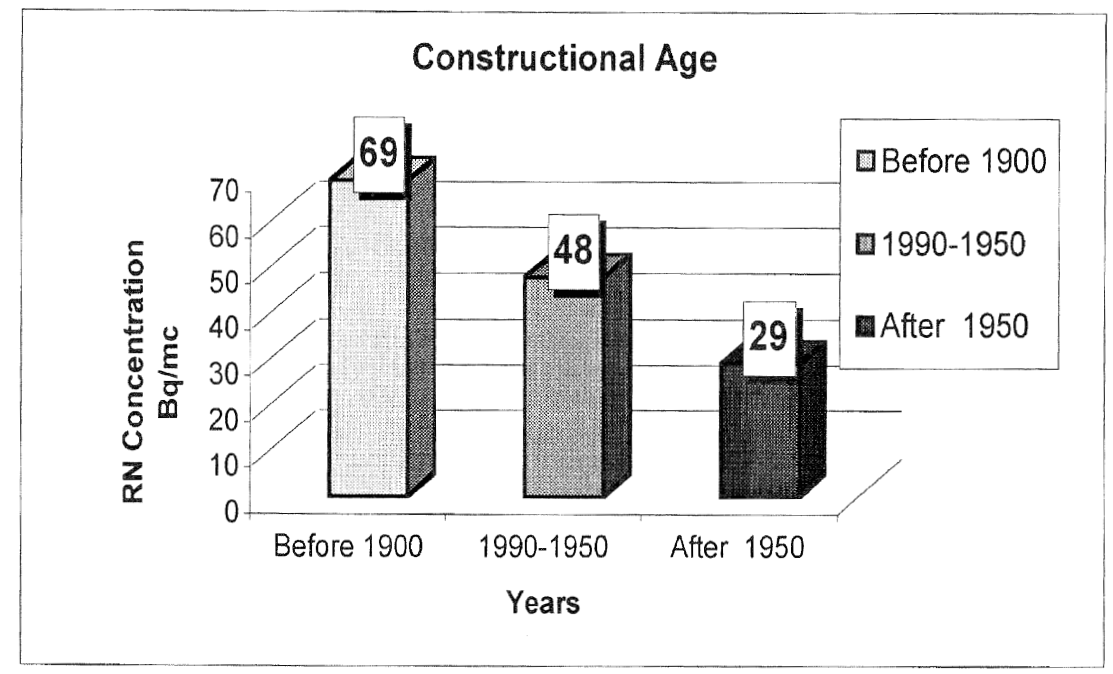

Figure 5: Constructional Age.

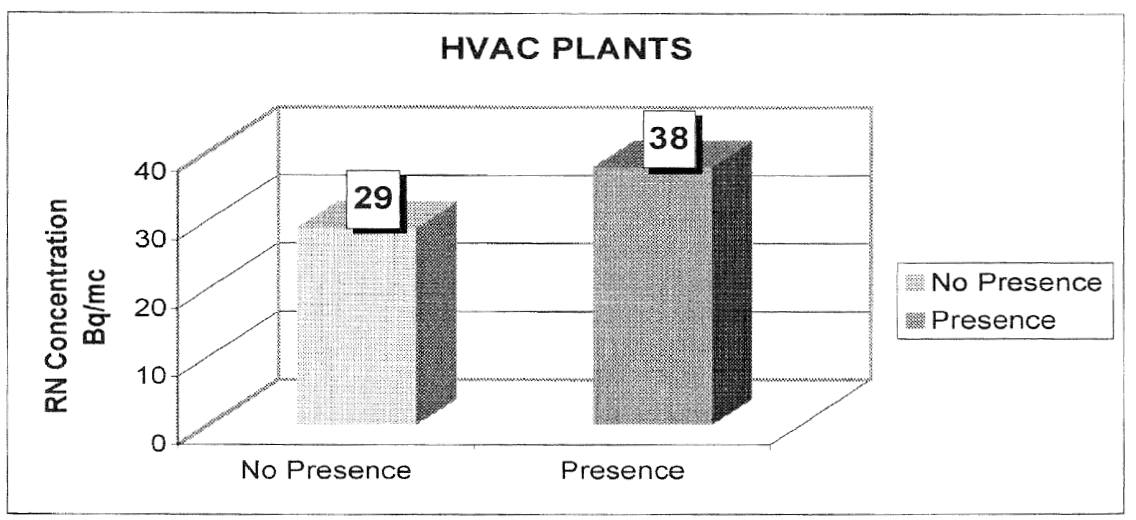

Figure 6: Allocation of Buildings 


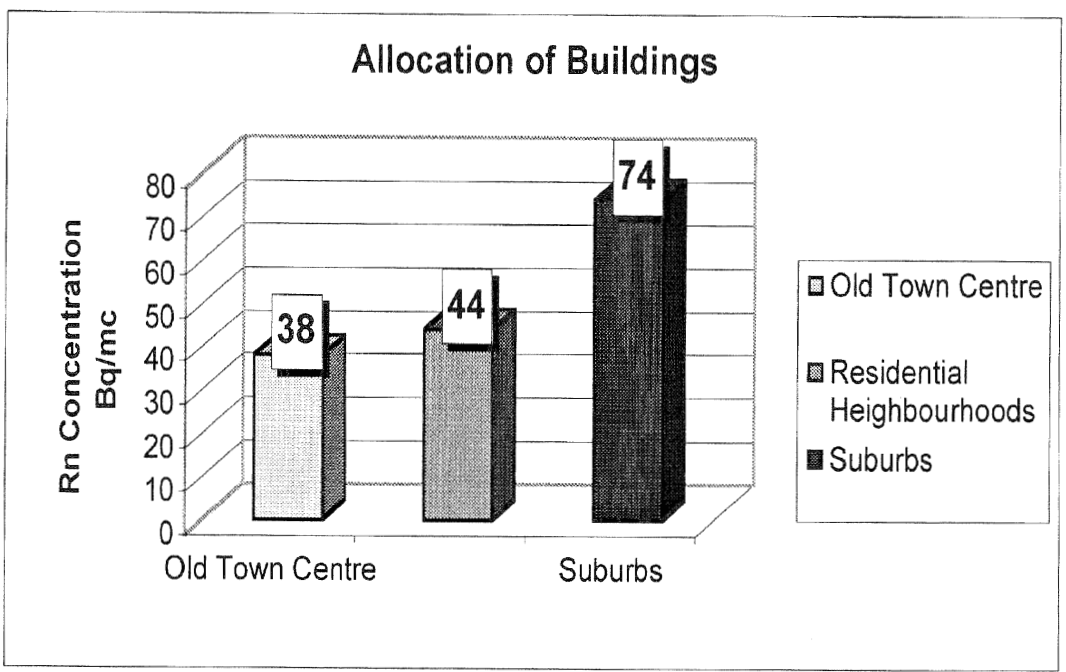

Figure 7: Presence of HVAC Plants.

\section{Conclusion}

Analysis of results support that, because of Radon comes from subsoil and seeps into the edifices through the basements or foundation grounds, there are three possible ways to control indoor Radon, that is: to block the entry of air coming from subsoil, to cause a strong indoor air change or to have some equipments that pull down indoor values of radiation. The first and second ways are strongly influenced by previously analysed parameters and it is in our opinion that there is not a general rule valid for all buildings to control $\mathrm{Rn}$ pollution but it is possible to assemble, in function of constructional peculiarities and utilisations some typologies as an unique flow dynamics system as regard entry paths and indoor store of Radon to the aim only to choice the must suitable and economic way which reduces indoor radiations to safety limits. On this ground and through propter cost analysis has been built by authors a general guidance that links the must representative typologies of buildings of Italian sceneries with the must economic indoor pollution control technics suitable for each typology, that is: ASD (Active Soil Depressurisation) (Flowler et al., 1991) (Henchel, 1993), SRER (Sealing Radon Entry Routes) (EPA, 1991) (Scott A., 1992), BPC (Buildings Pressure Control) [Patania and Gagliano, 1994) (Pyle and Leavic, 1991), AIT (Indoor Ionisation Technics) (Lo Nigro and Patania, 1998). Because of room reasons the cost analyses in function of buildings typology and the general guidance to choice the control technics must be reported in future "part two" of report. 
50 Environmental Health Risk

\section{References}

Lo Nigro S., Patania F., 1999. "A new Method to Control Health Effect of Radon Air Pollution" Final report in the III $^{\text {rd }}$ International European Workshop Radon in the Living Environment, Athens, Greece

Windham, S.I. and Gray, D.J., 1987. "EERF Standard Opearating Procedures for Radon-22 measurement Using Charcoal Canisters", EPA 520/5-87-005, U.S. Environmental Protection Agency, Montgomery, AL

Patania F., Gagliano A.,1994. "Radon Pollution Dynamics in Indoor Environment: Proposal about its Control" Proceedings of International Healthy Buildings. Budapest, Hungary

Rudnick S.N., Hinds W.C., Maher E.F., Price J.M., Fujimoto K., GuFang and First M.W.1982"Effect of Indoor Air Circulation Systems on Radon Decay Product Concentration". EPA contract 68-00106029, Harvard School of Public Health. Boston.

Flowler C.S., Willimson A.D., Pyle B.E., Belzer F.E., and Coker R.N. 1991. Handbook:" Design and Installation of a Home Radon Reduction System. Subslab Depressurisation System in Low Permeability Soil" EPA/625/6-91/029 (NTIS PB93-116234).

Henchel D.B.1993."Radon Reduction Techniques for Exiting Detached Houses: Technical Guidance for Active Soil Depressurisation System". EPA/25/R-93011/030.

Environmental Protection Agency,1991 "Radon -- Resistant Construction Tecniques for New Residential Construction - Technical Guidance" EPA/625/291/032.

Scott A.,1992, "Sealants for RN Exclusion" .Healthy Physics, Vol.2 No.6.

Pyle B.E. and Leavic, K.W.1991." A comparison of Radon Mitigation Options for Crawl Space School Buildings". Proceedings of The 1991 International Symposium on RN and RN Reduction Technology, EPA/600/9-91-0376 Vol.2, pp 10-73.

Lo Nigro S. ; Patania F.,1998. "Control Techniques of Indoor Radon Pollution". Proceedings of The IInd World Clean Air and Environment Congress. Durban, South Africa. 